\title{
LA NEGATIVIDAD EN HEGEL Y LA KEHRE HEIDEGGERIANA
}

\author{
Emmanuel MEjfA \\ Universidad de Lausana
}

RESUMEN. Este artículo se propone como tarea desarrollar lo que está en la raíz de la interpretación heideggeriana de Hegel -y, más precisamente, de la interpretación que se da a partir de la dimensión de la "historia acontecida del ser (die Geschichte des Seins)" en la cual el pensamiento de Heidegger se mueve definitivamente a partir del año 1936-. En oposición a todo interés «histórico (historisch)", Heidegger ve en la negatividad hegeliana el anuncio "ontohistórico (geschichtlich)", pero al mismo tiempo denegado, del recusamiento (Verweigerung) del ser en su verdad. Este anuncio es lo que está por venir de manera escondida en Hegel, y entonces constituye lo que podemos llamar «el porvenir de Hegel». Pero al mismo tiempo el porvenir de Hegel, como el porvenir de toda posición de fondo de la metafísica, remite según Heidegger al ugiro en el acaecimiento propicio (die Kehre im Ereignis)». En este sentido, lo específico de Hegel sería que, en su experiencia de la negatividad, se anuncia la lejana venida de la Kehre heideggeriana.

Interpretar a Hegel ha sido algo decisivo tanto para Gadamer como para Heidegger. Obviamente, no podemos aquí reconstruir esas dos lecturas de Hegel: una tarea, aunque todavía no cumplida, fundamental para evaluar la influencia del legado de Gadamer. Pero precisamente para acercarse a ello resulta imprescindible tener claramente a la vista el sentido de la interpretación heideggeriana de Hegel, sobre todo la por él llevada a cabo a partir de los años 1936-38 hasta su muerte, o sea, a partir de la dimensión de la historia acontecida del ser (die Geschichte des Seins), en la cual se mueve definitivamente su pensar desde esas fechas. Este artículo se propone contribuir a esclarecer esta última tarea. 
Nuestra pregunta conductora es la siguiente: ¿cuál es la relación entre la interpretación heideggeriana de Hegel y la historia acontecida del ser? Según nosotros, remite a la recepción que se hiciera de Heidegger en relación con la actualidad y el porvenir de Hegel.

En efecto Heidegger, inmediatamente después de la publicación de Ser y Tiempo, se ha visto confrontado a un tipo de recepción que pretendía hacer de su pensamiento una especie de actualización de la metafísica absoluta de Hegel. Como muestra ya este pasaje del curso de 1930-31 sobre la Fenomenología del espiritu: "Hay quienes se esfuerzan hoy en día en probar que la problemática de Ser y Tiempo se encontraría ya en Hegel». Y Heidegger añade:

Tanto esfuerzo denodado por mostrar que Ser y Tiempo no es sino una vieja historia debe ejercer sobre el autor un saludable efecto moderador. [...] Pero otra cosa, decisiva, es saber si, con tales maquinaciones astutas, se le puede hacer un favor a Hegel y hasta honrar su memoria, algo que debe ser ciertamente refutado. ${ }_{\mathrm{j}}$ Pues si existe un autor de quien sería realmente un contrasentido atribuirle la problemática de Ser y Tiempo, es justamente Hegel! En efecto, la tesis: la esencia del ser es el tiempo es precisamente lo contrario de lo que Hegel intentó revelar en toda su filosofía. La tesis hegeliana debe tener, en cambio, un sentido inverso: el ser es la esencia del tiempo ${ }^{1}$.

Esta desafortunada comprensión que se tenía de Heidegger sobre su relación con Hegel va a perdurar, hasta el punto de que casi cuarenta años después, en el protocolo de un seminario consagrado a la conferencia Tiempo y Ser, Heidegger se sentirá de nuevo obligado a clarificar su relación con Hegel: «En este seminario fue menester dar por supuesto el conocimiento y la experiencia de la historia de la metafísica, en la medida en que no había posibilidad de hacer referencia expresa a los nexos históricos entre pensadores ni a las posiciones metafísicas particulares. La única excepción fue Hegel, al que se trató detenidamente y con propiedad, y ello por el hecho, digno de nota, de que, cada vez más y de las más diversas maneras, el pensar de Heidegger ha sido comparado con el de Hegel" ${ }^{2}$.

${ }^{1}$ Cf. Martin Heidegger, Hegels Phänomenologie des Geistes, GA 32, 208s. Salvo indicación expresa, todas las obras citadas son de este autor; la referencia apunta a la Gesamtausgabe (=GA) ed. por Klostermann, Fráncfort del Meno. Cf. también Metaphysik und Nihilismus, GA 67, 171.

${ }^{2}$ "Protokol zu einem Seminar über den Vortrag "Zeit und Sein" (1962); en Zur Sache des Denkens, Niemeyer, Tubinga, 1969, p. 28 s. 
Así que la insistencia heideggeriana en continuar su controversia con Hegel respondería a la necesidad de tener que demarcarse una y otra vez de éste, o sea, de mostrar, en contra de las opiniones filosóficas vigentes, que por detrás de la supuesta semejanza se daba un neto y decisivo contraste. Es más, respondería a la necesidad de mostrar que esa apariencia descansaba en el fondo sobre la incomprensión de la diferencia, y por ende de la relación, entre la cuestión del ser y la pregunta conductora de la metafísica por el ente como ente o, como Hegel la llama en la introducción de su Fenomenología, por aquello que es en verdad.

Mas al aludir a ello estamos ya indicando la relación entre la recepción de Heidegger y la actualidad ontohistórica de Hegel según Heidegger. De hecho, la incomprensión de la diferencia entre Hegel y Heidegger descansa a su vez en el completo achatamiento de la existente entre las cuestiones conductoras de ambos proyectos: de un lado la metafisica, que toma en Hegel la forma de exponer en un sistema de la ciencia (y como tal sistema) la verdad del ente o la entidad (Seiendheit), en cuanto que este proceso - que no es sino el del absoluto mismo- ha de pensarse a sí mismo absolutamente y producirse como saber absoluto de sí mismo; del otro la no-metafisica, la pregunta por el ser en su verdad, verdad que no debe nada al ente pero que requiere ser fundada por el hombre, en cuanto que es éste quien asume su guarda y custodia. Ahora bien, en la nivelación de aquello que Heidegger llamó durante un tiempo "diferencia ontológica» - un olvido determinante en la actualidad del fin de la metafísica-, Hegel habría jugado, según Heidegger, un papel destacado. Habría sido aquél, en efecto, el que asegurara de una manera decisiva esa nivelación, cumpliendo cabalmente con el movimiento constitutivo de la metafísica, consistente en: 1) la transición del ente -nominalmente, aquello que es-a su ser - verbalmente, la esenciación o despliegue-, y 2) la comprensión exclusiva de este movimiento a partir del ente, dado que la metafísica, aunque atienda al valor "verbal dentro del nominal» ${ }^{3}$, sigue comprendiendo de antemano lo verbal en el horizonte de lo nominal, de lo sustantivo. Según eso, Hegel es entonces el nombre propio de este evento final en la historia de la metafísica, a saber: el aseguramiento de que no haya nada del ser aparte del ente, dando con ello libre curso a nuestra época, en la que el ente resulta vaciado de su ser por el incesante proceso de fabricación maquinada de abstractas y anónimas mercancías, perfectamente disponibles e

${ }^{3}$ Cf. Jean BEAUFRET, "Le sens de la philosophie grecque", en L'enseignement par excellence. Hommage à François Vezin, ed. P. David, L'Harmattan, París, 2000, p. 40, n. 4. 
intercambiables. Es esta actualidad de Hegel la que hace escribir a Heidegger, en el volumen 68 de la Gesamtausgabe, titulado Hegel:

Todo el idealismo alemán, y la filosofia de Hegel en particular, han desplegado el efecto de una fuerza ontohistórica de cuya influencia, alcance o límites no tenemos hoy todavía ninguna medida, dado que estamos sumidos en ella por todas partes, sin reconocerla como tal. [...] Sin el idealismo alemán, y sin la metafísica de Hegel en particular, el positivismo del siglo XIX y de nuestro presente nunca hubieran podido lograr la solidez y evidencia que le son propias. La época en la cual Nietzsche estaba pregnantemente enraizado es impensable sin Hegel; inútil es decirlo con respecto a Marx y al marxismo, siendo algo más que una cierta formulación del socialismo. [...] Por todas partes sigue siendo Hegel eficiente, aun cuando ello tenga en todo caso lugar de un modo invertido y disfrazado, o incluso como movimiento en contra de él'

La necesidad de la controversia con Hegel no reside, pues, solamente en la desafortunada recepción que se ha hecho de Heidegger, sino que viene más profundamente requerida por la secreta vigencia de Hegel en nuestra época actual, determinada por la cumplimentación del ya mencionado doble movimiento constitutivo de la metafísica.

Y sin embargo, este segundo motivo sigue siendo todavía insuficiente, porque, dentro de lo que se juega con y en Hegel, no muestra sino aquello que salta más a la vista. Late aún por debajo, de un modo imperceptible, algo que no se limita a hacer señas hacia la actualidad de Hegel, sino que apunta a su porvenir. Para ver el correlato escondido del aseguramiento definitivo del ser como entidad del ente, podemos por ejemplo partir de lo dilucidado por Heidegger en Besinnung, por lo que hace a la cuestión de la metafisica.

Hacia el final de esta obra, precisa Heidegger esa cuestión: «la metafísica es la verdad de lo ente como tal y en su conjunto, manteniendo en todo caso separada de él toda fundación de la verdad del ser a partir del eseyer, y ello en virtud

${ }^{4}$ «1. Die Negativität. Eine Auseinanderserzung mit Hegel aus dem Ansatz in der Negativität (1938/39, 1941)", en Hegel, GA 68, 7s. 
del propio desprendimiento (Loslassung) del ente, en su preeminencia sobre el ser de una tal verdad (estar abierto en cuanto estar al descubierto)»" Lo así inaparente en Hegel es pues la consumación del impedimento por parte de la metafísica de toda fundación de la verdad del eseyer a partir de él mismo. Ahora bien, ese impedimento, que yace secretamente en el fondo de aquello que Heidegger llama en los Aportes "el abandono del ser (die Seinsverlassenheit)" ", no proviene de una deficiencia de los pensadores de la metafísica, sino del eseyer mismo, en cuanto que éste - según señala Heidegger en Besinnung - "mantiene oculta (verbirgt) la posibilidad de su verdad y de su fundación". Ese ocultamiento (Verbergung) es a su vez "recusamiento (Verweigerung) procedente del eseyer mismo, el cual —como un destino- envía fuera de él (weg-schickt) la entidad vacía, como contraesencia (Unwesen) suya en el olvido del ser" ${ }^{7}$. El ser como eseyer se rehusa en su verdad, rechazando así su fundación, transfiriendo (überlä $\beta t$ ) al ente la entidad y permitiendo (zuläßt) con ello que ésta se despliegue como ser del ente, es decir como su fundamento general ulterior (nachträglich), constituyendo entonces su propiedad. Pero, mientras el eseyer se oculta así como recusación de sí mismo en su verdad, no deja al mismo tiempo de preservarse en verdad (sich verwahrt) «hacia una única donación (Schenkung), que no deja huellas (spurlos) ni tiene poder (machtlos) " ${ }^{8}$. Que la metafísica sea así «la juntura del desocultarse del ente (die Fuge der Entbergung des Seienden) en vista de que éste sea lo descubierto y de que su esencia, el ser-descubierto, se determine como entidad, en el sentido de la continuidad en el propio hacer acto de presencia (Beständigung der Anwesung)" ${ }^{9}$, no significa sino que ella es al mismo tiempo la historia del nosaber y del no-preguntar por la recusación del eseyer y de su verdad. Esto último es justamente eso que la metafísica no ha podido asumir, pero que ha permitido al mismo tiempo su despliegue. Y Hegel ocupa un lugar destacado en la metafísica, es decir, en la historia del rechazo de la recusación, en el sentido de que ese rechazo no se encuentra guardado ni fundado por ella. En efecto, es Hegel - señala Heidegger- el que lleva a cumplimentación la metafísica articulando, gracias a la organización absoluta del concepto, el desocultamiento del ente en tanto que exposición absoluta del saber de sí mismo del absoluto, y ello expues-

Cf. Besinnung (=B), GA 66, 382.

${ }^{6}$ Cf. Beiträge zur Philosophie (=BzPh), GA 65, 110s.

${ }^{7}$ Cf. B. GA 66, 364.

${ }^{8}$ Cf. B. GA 66, 200.

${ }^{9}$ Cf. B. GA 66, 368. 
to en ese Sistema de la Ciencia en que se convierte entonces la filosofía. De este modo, Hegel rechaza (literalmente: "des-dice», ab-sagt) la recusación del eseyer en su verdad, o sea: lo dice al tiempo que niega decirlo ${ }^{10}$. Ahora bien, este advenir que es «la verdad del eseyer como recusación», en cuanto rechazado (desdicho) por Hegel, no es al mismo tiempo, para Heidegger, sino aquello que está por venir en Hegel, y que guarda por ende el porvenir de Hegel. Un porvenir que es también el del "otro inicio" (des anderen Anfangs) del pensamiento occidental en tanto que este des-decir la recusación puede tornarse (sich kehren) en su guarda en verdad (Wahrnis), en su fundación (Gründung) y en el salvamento (Bergung) por parte del Dasein mortal del ente como propiedad del ser: algo que llevaría entonces en último lugar a un despliegue del ente totalmente distinto del actual. Sabemos, al menos, en nuestra época de transición al otro inicio, que en éste no será ya el ente nunca más lo real efectivo en el sentido de lo presente de manera constante ${ }^{11}$.

Tal es según creo el tercer y decisivo motivo de la insistencia con la cual Heidegger medita sobre Hegel. Una motivación no guiada por un interés de actualidad, sino por lo que está por venir en Hegel. La lejana venida del otro inicio puede y debe entonces leerse en Hegel en su denegación de la recusación del eseyer en su verdad. Así que la interpretación ontohistórica de Hegel no es exterior a la cuestión en busca de la verdad del eseyer y su destino: la interpretación, conforme a destino, de lo que inaparentemente viene en él, es ya la ontohistoria del otro inicio del eseyer. Como Heidegger señala en Besinnung: «lo que está al venir (das Zukünftige) no viene ante todo después de esta presente época a la manera de un sueño romántico, sino que más bien es ya advenido (angekommen) y está confiado (verschenkt) al recuerdo ontohistórico del eseyer en tanto que recusación»" ${ }^{12}$.

Si hay la posibilidad de un giro en la historia acontecida del eseyer, entonces la suerte de este giro, en espera de ser pensado, ha venido ya a refugiarse secretamente en el pensamiento de Hegel, lo mismo que en cada posición metafísica de fondo, aunque de un modo peculiar en aquel caso.

${ }^{10}$ Cf. $B z P h$. GA 65, 406. A mi ver, el miedo de Hegel a la naturaleza y a la locura se puede interpretar como síntoma de este rechazo, de este des-decirse de la recusación del eseyer.

11 Cf. BzPh. GA 65, 257.

12 Cf. B. GA 66, 277. 
Preguntémonos ahora: ¿En qué sitio se halla en Hegel la suerte del giro? Heidegger aventura una respuesta, indicada ya en el título mismo del primer texto del mentado volumen 68: "La negatividad. Una controversia con Hegel a partir del planteamiento (Ansatz) de la negatividad». La negatividad es en efecto, para Heidegger, esa determinación de fondo (Grundbestimmung) en Hegel cuya "travesía pensante (Durchdenkung) reconduce a un plan más originario, porque es solamente a partir de éste como la negatividad puede ser realmente apercibida en cuanto tal determinación de fondo", mientras «sigue siendo conforme a lo que el sistema hegeliano ha elaborado» ${ }^{13}$.

Con el fin de pensar la ontohistoricidad de la negatividad hegeliana, Heidegger se orienta de manera implícita sobre tres aspectos que podemos calificar - moviéndonos dentro de la conceptualidad hegeliana - de lógico, fenomenológico y sistemático. En efecto, la negatividad es -como Heidegger escribe a Jünger ${ }^{14}$ - el rasgo fundamental (Grundzug) de la metafísica absoluta de Hegel, siendo las partes fundamentales de esa metafísica: 1) la Ciencia de la Fenomenología del Espiritu, es decir el saber del absoluto en tanto que se le aparece a la conciencia, y en su seno, a fin de llegar a partir de ella al saber de sí, asegurando con eso absolutamente el elemento del saber absoluto (o sea, de la Ciencia); y 2) la Ciencia de la Lógica, o sea, la ciencia del absoluto tal como, en y para sí, es inmanente a sí mismo, "antes» de su doble revelación de sí en la naturaleza (Filosofia de la Naturaleza) y en el espíritu (Filosofia del Espiritu). Por consiguiente, es claro que la negatividad debe tener un respecto fenomenológico y otro lógico; dos respectos que deben confluir en: 3) el universal concreto, o sea, en el respecto sistemático, propio del Sistema de la Ciencia en su totalidad.

1. La cara fenomenologica de la negatividad viene expuesta en la Introducción a la Fenomenologia, siendo esa negatividad entendida por Hegel como diferencia de la conciencia. La conciencia es diferencia en la medida en que se diferencia, se di-vide entre (unterscheidet sich) la conciencia natural o no-verdadera (conciencia de algo) y la conciencia de sí o verdadera (una verdad que se despliega plenamente como espíritu sabiéndose absolutamente, o sea, como saber absoluto). Ahora bien, esta escisión respecto de sí misma constituye el espacio de juego del movimiento dialéctico-especulativo que es la experiencia de la conciencia. Por

${ }^{13}$ Cf. «Die Negativität», en Hegel, GA 68, 6.

${ }^{14}$ Cf. «Zur Seinsfragem, en Wegmarken, GA 9, 404. 
este movimiento, y en él, la conciencia verdadera, en diálogo consigo misma en su aspecto de no-verdadera, reorganiza retrospectivamente la historia de la travesía de sí en todas sus figuras no-verdaderas, o sea: la historia de su necesaria autosupresión en su no-verdad (lo propiamente dialéctico del proceso) y de su elevación, en el seno de este movimiento dialéctico, a una nueva configuración momentáneamente verdadera (que es lo propiamente especulativo del proceso).

Ahora bien, la posibilidad de este movimiento descansa en el hecho de que el paso de una figura de la conciencia a la otra no desemboca simplemente en un resultado negativo, como cree el escepticismo abstracto, sino en el lugar en que acontece lo positivo, eso que la conciencia no-verdadera no puede aprehender sino como el nuevo objeto verdadero, no como devenir o proceso. Se trata, según Hegel, de considerar la positividad, es decir lo que es verdadero a cada momento del proceso, como resultado, o sea, como lo que resulta de la negación de la negatividad propia de cada figura de la conciencia. En suma, la conciencia verdadera se gana a sí misma a través del proceso exhaustivo de toda su no-verdad o negatividad. Pero eso es posible solamente si la negatividad propia de cada configuración de la conciencia se relaciona consigo misma y retorna sobre sí misma, gracias al movimiento retrospectivo por el cual la conciencia verdadera se revuelve sobre la conciencia no verdadera (Umkehrung), haciendo que ésta experimente la negación de la negatividad que esa última contiene en sí.

Así pues, la negatividad no es instrumento formal que se pueda aplicar desde fuera a cualquier objeto, y menos a la conciencia. Al contrario: la conciencia despliega su ser qua diferencia, diferencia que permite su devenir verdadero por la negación de toda la negatividad propia de su no-verdad. Pero, con eso, esta diferencia no es precisamente tal, según Heidegger, porque ella está ya desde siempre nivelada en la negación de la negatividad de lo no-verdadero, en cuanto sitio de la necesidad de que venga a sí mismo el absoluto en su saber de sí, apareciendo en la conciencia humana. La negatividad absoluta no es sino una astuta privación o desposesión que de sí mismo hace el absoluto en su aparición a sí mismo cabe el espíritu finito, en vista de la plena e íntegra toma de posesión de sí mismo, tal como debe exponerse en la filosofía en tanto que sistema de la ciencia.

A partir de este punto, es ya posible entender en qué constituye esta negatividad fenomenológica, en suma, una renuncia, un des-decirse de la recusación 
del eseyer en su verdad. Pero para captar tal cosa con claridad es preciso reconocer, en el movimiento de autoposición del saber absoluto en la conciencia humana -o lo que es lo mismo, en el movimiento del devenir verdadero de la conciencia a partir de la negación de su negatividad propia en cuanto conciencia no-verdadera-, es preciso reconocer - digo- el movimiento meta-físico que va del ente a su ser en cuanto entidad. Movimiento transformado y refractado en la conciencia, en el sentido de que la conciencia ontológica o verdadera, en tanto que conciencia de sí plenamente desplegada en y como saber absoluto del espíritu, adviene a sí misma y se pro-duce a sí misma mediante la negación de la negatividad propia de la conciencia óntica (en Hegel, la conciencia natural o noverdadera). Ahora bien $-\mathrm{y}$ tal es en definitiva la transformación del movimiento meta-físico llevado a cabo por Hegel-, este saber óntico no es en cada caso sino una faz privativa del saber ontológico o absoluto. Saber absoluto que, para advenir a sí mismo, comienza necesariamente por aparecerse gradualmente en y como saber óntico. Por consiguiente, en Hegel, este movimiento de trascendencia está constituido por la venida a sí misma de la entidad a partir, primero, de eso que Heidegger llama su de-strucción $(A b b a u)$ y, en segundo lugar, de su reconstrucción, mediante la negación de sus respectos negativos. La Fenomenologia del espiritu, pues, en virtud de la organización absoluta de la negación de toda privación de la entidad de lo ente, no constituye al mismo tiempo sino la autoproducción absoluta del dominio de la entidad, o sea, del absoluto en su proceso de saberse a sí mismo.

En suma: con la Fenomenología del espiritu queda asegurada la autoproducción del dominio del ser como entidad del ente, en cuanto recolección de todas las co-yunturas de la verdad del ente en su entidad. Es entonces este aseguramiento - que Hegel llama en su Ciencia de la lógica deducción del concepto de la ciencia ${ }^{15}$ - lo que va a permitir a la filosofia especulativa o lógica el desplegarse de sí misma en toda su verdad, así como en sus dos revelaciones (Offenbarungen): la filosofia de la naturaleza y la filosofia del espiritu.

Ahora bien, si pensamos eso a partir del ser en su verdad, es decir como eseyer y no como entidad del ente, el aseguramiento tiene todavía otra cara: la de la exclusión de la di-visión entre (Unter-scheidung) el ser como eseyer y el ente como su propiedad (Eigentum). Porque, si el sentido del ser queda asegurado

${ }^{15}$ G.W.F. HeGEL, Wissenschaft der Logik (=WdL). Gesammelte Werke (=G.W.) 11, 20. 
como el devenir verdadero, dialéctico-especulativo, de lo ente, o, dicho de otra manera, si su entidad está asegurada de una vez en cuanto autoproducción de sí, en virtud del movimiento dialéctico-especulativo que hace experimentar al ente, queda al mismo tiempo asegurado el que no haya ya nada del ser en su verdad, del ser como eseyer. Das Seyn ist das Nichts. "El eseyer es la nada". En efecto, en Hegel, el ser qua entidad quiere por voluntad propia aparecerse cabe nosotros, entes finitos pero con autoconciencia, entendiendo esa manifestación como un aspecto de la autoproducción de sí mismo. Sólo que, entonces, el ser en su verdad queda des-dicho.

Y sin embargo, des-decir indica ya una manera (para Heidegger... y para Hegel, lo cual no significa que haya una dialéctica en Heidegger) de decir. Porque, en tanto que esta verdad del ser es precisamente la recusación de sí misma, viene ciertamente dicha en cada momento del proceso de la autoproducción del saber que aparece. La Fenomenología del espiritu tendría entonces como significación ontohistórica el constituir la organización -absoluta y retrospectivapor el concepto, de la historia, que es a lo que Hegel denomina en la Fenomenología la bistoria concebida ${ }^{16}$ : la historia de la aparición denegada de la recusación del eseyer a la conciencia humana.

2. Ahora bien, si es verdad que lo fenomenológico no es para Hegel sino la aparición de lo lógico en la conciencia, entonces hay escondida, detrás de la cara fenomenológica de la negatividad, un respecto lógico, tal como se expone, entre otras cosas, al principio y al final de la Ciencia de la Lógica, bajo la figura de la alteridad absoluta o del otro del otro. Hegel identifica, en efecto, la negatividad absoluta con la alteridad absoluta en el último capítulo de la Gran Lógica, relativo a la idea absoluta; y lo hace al explicar el movimiento del concepto absoluto, o sea, el método: «la negatividad considerada [e. d., la negatividad absoluta, E.M.] constituye ahora el punto de inflexión (Wendungspunkt) del movimiento del concepto. [...] En este viraje del método, el curso del conocer retorna al tiempo en sí mismo. Esta negatividad, [entendida] como la contradicción que se asume, constituye el restablecimiento de la inmediatez primera, de la universalidad simple [es decir, la inmediatez devenida, venida a sí misma, por haber regresado de toda mediación particular, E.M.]; porque, ahora, se da inmediatamente que

16 G.W.F. Hegel, GW 9, Phänomenologie des Geistes (=Phä). G.W. 9, 434. 
el otro del otro, lo negativo de lo negativo, es lo positivo, lo idéntico, lo universal. ${ }^{17}$. Lo que Hegel entiende exactamente por la expresión "el otro del otro», viene explicado en tres parágrafos de la Doctrina del ser, de la Lógica de la Enciclopedia $^{18}$. En ellos se trata de producir el concepto de la infinidad cualitativa -lo que él llama la "verdadera infinidad"— en oposición a la mala. Ahora bien, esa distinción se logra por medio del concepto del otro del otro. Dado que el entendimiento separa o "deja caer uno fuera del otro" los momentos de la existenciaóntica (Dasein) que son el "algo» (aliquid) y el «otro" (aliud), el infinito representa para él la serie sin fin de algo que llega a ser otro y de otro que no es a su vez sino algo limitado por otro (algo), y así al infinito. Al contrario de este infinito malo, el verdadero consiste más bien, dice Hegel: «en ser [en estar], en su otro, cabe sí mismo, o - expresándolo como un proceso- en llegar, en su otro, a sí mismo». Por tanto, algo es ya en sí mismo, en su relación a otro, un otro relativamente a otro. Y ello significa entonces que el ser-otro es tanto lo que hay en el tránsito como aquello que opera en el tránsito; la consecuencia, en definitiva, es que el tránsito de algo a otro, o del hacerse otro de algo, es al mismo tiempo un llegar a (ser) sí mismo en su otro. O lo que es lo mismo, pero dicho de manera negativa, es decir, a partir del otro y no del sí: el otro llega a ser el otro del otro. Con ello, concluye Hegel, el ser queda re-establecido en su infinidad verdadera en tanto que negación de la negación, o respectividad a sí misma de la negación ${ }^{19}$. En suma: la negación de la negación queda identificada con el otro del otro. Aquí se echa de ver cómo Hegel, en su identificación de lo negativo con el otro, está siguiendo el Sofista de Platón, según atestigua el capítulo de la Historia de la Filosofia hegeliana dedicado a Platón: Hegel vuelve a tomar, en efecto, como resultado fundamental el que "el no-ser, determinado más precisamente, es la esencia del otro" ${ }^{20}$. Ahora bien, si el ser del mè ón es el héteron, se sigue que, para Hegel, el óntōs ón queda probado como el héteron del héteron, o sea, como negatividad absoluta.

Con todo, en esta recuperación de la dialéctica platónica se necesita todavía que el héteron se refiera a sí mismo por la reflexividad moderna absoluta del pen-

\section{Cf. WdL. G.W. 12, 247.}

${ }^{18}$ Son los parágrafos 46 a 48 para la edición de 1817 o los parágrafos 93-95 para las ediciones de 1827 y 1830 .

${ }^{19}$ Cf. G.W.F. Hegel, Enzyklopädie, $\$ 94, Z$ usatz, y $\$ 95$.

${ }^{20}$ Cf. G.W.F. HeGeL, Vorlesungen über die Geschichte der Philosophie (= VGPh.). Plato (cito en este caso por la tr. fr. —según Ms.- de P. Garniron, Vrin, Paris, 3, 444s.). 
samiento absoluto que se piensa absolutamente. Y ello es lo que hará decir a Heidegger en Besinnung que la negatividad de Hegel es la transposición (Versetzung) del mè ón platónico en el pensamiento absoluto ${ }^{21}$. En esa transposición, Hegel vuelve a poner en juego el platonismo, desactivando de este modo la dimensión abisal del ser, al reducirla a simple privación al servicio del absoluto qua entidad de lo ente. Para Hegel no existe lo falso ${ }^{22}$, sino solamente lo no-verdadero: el noente, o sea, ese «no", por corresponder todavía plenamente al ente, se revela como "ser-otro", perteneciendo ya desde siempre al ser en cuanto entidad, con lo que este último llega a ser, en tanto que proceso de su autoproducción o devenir de sí, el otro de su otro, que es lo que cada ente es. Tal es la forma lógica del rechazo, del des-decirse de la recusación del eseyer, como se testimonia en la negatividad hegeliana.

A su vez, ese des-decirse se destaca por su ambigüedad (Zweideutigkeit). Por un lado, la recusación queda en entre-dicho porque el movimiento meta-físico está ya en cada caso previa y necesariamente seguro de que la negatividad absoluta tendrá lugar bajo la forma del otro del otro. Por otro lado, sin embargo, esa recusación no deja de estar al mismo tiempo dicha porque, en el proceso así descrito, el ser no puede desplegarse como lo totalmente otro con respecto a lo ente, sino solamente como la privación absoluta de todo lo privativo del ente como tal; algo que, en definitiva, sigue siendo propio del ser en cuanto entidad del ente.

3. Ahora es preciso hacer ver que estas diferentes formas de negatividad están ya desde siempre proyectadas por Hegel en el horizonte del pensamiento absoluto, articulando por ello el espacio de juego de su diferenciación de si consigo, por y dentro de la cual puede llegar a ser lo que es, y a ser, entonces, plena y enteramente siendo, o sea, siendo entidad en cuanto proceso de exposición absoluta de sí de lo ente, como tal y en su conjunto, en la filosofía entendida como sistema de la ciencia. Así, esta negatividad absoluta (que no es otra cosa sino esa diferenciación de sí consigo afirmada y negada a la vez, o sea: siendo inmediatamente negada a fin de ser de nuevo afirmada) no es en este proceso sino aquello que mueve sin ser movido, de modo que el pensamiento piense absolutamente al absoluto como pensamiento. $\mathrm{O}$, como dice Hegel en su gran texto -el Prólogo, no a la Fenomenología sino al Sistema de la Ciencia en su totalidad-, la negatividad es

${ }^{21}$ Cf. B. GA 66, 293.

${ }^{22}$ Cf. Phä. Vorrede. G.W. 9, 30. 
"la energía del pensar" ${ }^{23}$. Ésta es la determinación fundamental de la negatividad - sobre la cual descansa además toda la lectura de Heidegger en el manuscrito Die Negativität-; una determinación que constituye su cara sistemática. La negatividad absoluta como energía del pensar absoluto sería entonces esa fuente hacia la cual remontarían en todo caso sus otras determinaciones. ¿Qué es lo que Hegel entiende aquí por energia? Entiende nada menos que la traducción de la enérgeia de Aristóteles, haciendo resonar en ella términos como Wirksamkeit o Tätigkeit ${ }^{24}$. En dependencia por lo tanto de las traducciones latinas de enérgeia por effectio o actus, Hegel reinterpreta la pareja dynamis-enérgeia a partir de la relación sujetoobjeto qua proceso propio del absoluto, siendo la sujetividad el respecto agente y la objetividad el paciente. Por eso dice Hegel que «el elemento platónico es en general el elemento objetivo, pero le hace falta el principio de vitalidad, de la subjetividad; un principio de vitalidad y de subjetividad específico de Aristóteles". Mientras que la posibilidad es el elemento objetivo, la energía no es sino la subjetividad, o sea, ese modo del pensamiento que, al hacer propiamente que sea toda cosa-que-es, es, en cuanto tal subjetividad, y como dice el propio Hegel, «ella misma todas las cosas en su presencia a sí" ${ }^{25}$. El pensar absoluto opera así el transcensus del ente a su ser qua entidad por el proceso de de-strucción y re-construcción de él mismo. Ahora bien: eso que es entonces competencia de la energía del pensar absoluto no es en el fondo sino el movimiento por el que la negatividad se refiere a sí misma. Así, lo "dicho" en la cara sistemática de la negatividad enuncia entonces esta proposición especulativa: la negatividad absoluta es la energía del pensar absoluto, y la energía del pensar absoluto es la negatividad absoluta.

De este modo, la negatividad, en Hegel, se encuentra desde siempre integrada al horizonte de la subjetividad del pensar absoluto. Y es esa integración la que constituye el des-decir sistemático de la recusación del eseyer en su verdad. La energía de la autoproducción del ser como entidad en el pensar absoluto se constituye por el acto de referir sistemáticamente la negatividad de cada ente, que no es sino, en cada caso, una limitación o privación del ser mismo, a ella misma, con el fin de que se disuelva y produzca con eso, en cada estadio del proceso del devenir del absoluto, su positividad momentánea. Así escribe Heidegger, en Die Negativität:

${ }^{23}$ Phä. Vor. G.W. 9, 27.

${ }^{24}$ VGPh. II, ed. Suhrkamp, Fráncfort del Meno, 1971, 19, 154.

25 VGPh. II. 19, 214. 
Cómo haya que ver [...] la completa disolución de la negatividad en la positividad del absoluto. La "negatividad» es la «energía» del pensar incondicionado, porque, desde el inicio, ha abandonado ya (darangegeben) todo negativo, todo lo que es al modo de "no" (Nichthafte).

De ese des-decir la recusación del eseyer da testimonio igualmente el hecho de que la integración de la negatividad en la positividad del proceso (o sea, la negación de sí en su negatividad) no le plantea problema alguno a Hegel. Como escribe Heidegger, la "pregunta en pos del origen de la "negatividad" no tiene ni sentido, ni fundamento [para Hegel, E.M.]. La negatividad es algo que no plantea cuestión ninguna» ${ }^{26}$.

Sin embargo, si por un lado queda así atestiguado el sistemático des-decir de la recusación del eseyer en su verdad, por otro lado la irrupción -igual de sistemática - de la negatividad en forma de negatividad absoluta que se refiere a sí misma absolutamente, es decir, la autoproducción del absoluto en sistema, dice al mismo tiempo y en cada caso la reincidencia - siempre al mismo tiempo denegada - del carácter abismático (Abgründigkeit) del eseyer. Y ésa es la razón por la que Heidegger puede decir en Besinnung que Hegel ha reconocido ya de cierta manera la negatividad propia del ser, pero que sólo lo ha hecho en el seno de la entidad ${ }^{27}$, asegurando así y llevando a cabo en el fondo el movimiento meta-físico, entendido como comunicación absoluta del ente y del ser qua entidad. Con eso, según Heidegger, la negatividad no es considerada en serio, porque desde siempre queda "engullida" por la positividad del proceso, que es el pensar absoluto del absoluto. En suma, la negatividad no deja de estar así prisionera de la recusación del eseyer, a saber, del abandono de lo ente al ser qua entidad, con lo que la negatividad se convierte en algo inocuo y sin peligro, ungefäbrlich.

Ahora bien, quitando así a la negatividad su peligro, Hegel impide que el peligro, die Gefahr, pueda mostrase como tal, als Gefahr, sin poder exponerse a su vez a la torna, a la Kehre, si es verdad, como dice Heidegger en la conferencia homónima, que «es en el peligro donde acaece en puridad la torna (in der Gefabr

26 "Die Negativität»; en Hegel. GA 68, 14.

27 B. GA 66, 293. 
ereignet sich die Kehre) ${ }^{28}$. Para dejar advenir el peligro que es la recusación del eseyer en su carácter abismático, preparando así «el acaecimiento propicio de la torna en el eseyer, el tornarse la recusación de su esenciar en el acaecer [en el lograrse] de su guarda en verdad (das Ereignis der Kehre im Seyn, die Kehre der Verweigerung seines Wesens in das Ereignen seiner Wahrnis) ${ }^{29}$, Hegel hubiera tenido que contestar a otra de-cisión (Entscheidung) del destino del eseyer y hacerse responsable de ella, yendo de un modo pensante más al fondo de cuanto se dice en esa fórmula que, al excluir (auschließt) la preservación de la suerte de la torna, al mismo tiempo la circunscribe (umschließt): Das Seyn ist das Nichts. No pensar ni decir: el ser es la nada como la más vacía abstracción de lo propiamente ente y de lo más ente, que es el pensar absoluto, sino: la nada pertenece al eseyer en su verdad; y más: la nada acaece, en este modo eminente de esenciación, como "el primer y más alto obsequio del eseyer (das erste und höchste Geschenk des Seyns)," ${ }^{30}$.

Pero Hegel sabía muy bien que la filosofía no podía ser sino la de su propio tiempo...

28 "Die Kehre»; en Bremer und Freiburger Vorträge. GA 79, 73.

29 "Die Kehre"; GA 79, 74.

30 B. GA 66, 295. 